\title{
LA MÚSICA RELIGIOSA A LA CIUTAT DE BARCELONA (SS. XVII-XIX)
}

Daniel Codina I Giol

2002, any centenari de la mort de Jacint Verdaguer

\begin{abstract}
A chronological account of the Kapellmeisters of the three principal sites in Barcelona: the Cathedral, the church of Santa María del Mar and the Palau de la Comtessa, including their compositions - most of which are ignored today as the scores have been lost- based on the printed booklets of the popular chants and oratories retrieved from the XVII to the XIX centuries. The account in question draws, in part, on the printed Cataleg dels villancets i oratoris impresos de la Biblioteca de Montserrat (ss. XVII-XIX), which the very author of this study has himself prepared and which is to be published in due course. The said catalogue will undoubtedly make a valuable contribution to the study of the history of music.
\end{abstract}

\section{Resumen}

Relació històrica i ordenada dels mestres de capella dels tres centres principals de la ciutat de Barcelona: la Catedral, Santa Maria del Mar i el Palau de la Comtessa i llurs obres -la majoria desconegudes perquè se n'ha perdut la música escrita- a partir dels llibrets impresos dels villancets i dels oratoris, en el període dels segles XVII-XIX. El treball aprofita part de l'obra Catàleg dels villancets i oratoris impresos de la Biblioteca de Montserrat (ss. XVII-XIX), que el mateix autor de l'article ha preparat i que està en curs d'edició i és una mostra de la utilitat d'aquest Catàleg per a conèixer de manera més precisa la història musical.

La confecció que he fet del Catàleg dels villancets $i$ oratoris impresos de la biblioteca de Montserrat, en curs d'edició, ens proporciona una gran quantitat de dades que ens serveixen per estudiar i conèixer més acuradament la realitat de la música religiosa no litúrgica de molts centres eclesiàtics i religiosos de la península ibèrica i, de manera molt concreta i especial, de la ciutat de Barcelona, lloc en el que se centrarà aquest estudi, el qual ajuda i completa en part els treballs de recerca del Dr. Josep Pavia, centrats principalment en la capella de música de la catedral barcelonina. ${ }^{1}$

D'una banda ens fan conèixer el gran treball creatiu dels mestres barcelonins dels tres centres més importants de culte i que en el camp musical tenien una exclusiva sobre les altres capelles musicals: la catedral, Santa Maria del Mar i el Palau de la Comtessa, i d'altra banda de

1. Els títols de les obres d'aquest musicòleg ja sortiran citats en les notes al llarg d'aquest treball.

Anuario Musical, 57 (2002) 
manera negativa, ens fan adonar de la gran quantitat d'obres musicals que s'han perdut, perquè dels 85 títols pertanyents a Barcelona ressenyats en el Catàleg, són poquíssims els que s'han conservat també amb la música corresponent.

Les obres -villancets i oratoris- de la ciutat de Barcelona representen un 26,7 \% del total de 318 títols del Catàleg. ${ }^{2}$ És notable, doncs, la presencia barcelonina en el conjunt i més tenint present que hi ha 37 localitats més en tot l'àmbit ibèric que hi aporten obres. Ben cert que, a nivell d'història de la música, no en podem treure cap conclusió, sinó només dir que aquests impresos barcelonins, ara individualitzats, devien formar part d'un o més reculls facticis relligats, igual que els que encara es conserven en aquest estat a Terrassa o a la Biblioteca de Catalunya, com era costum guardar-los. De fet, en l'estat actual en què es troben, es pot veure que havien estat relligats. Encara que siguin pocs (sis impresos), hi ha els que provenen del llegat Josep $\mathrm{M}^{\mathrm{a}}$ Casacuberta que recull alguns dels que s'havien interpretat a l'Oratori de Sant Felip Neri de Barcelona. ${ }^{3}$

Els mestres de capella. El conjunt ens proporciona el nom de tretze mestres, amb nom i cognom, que treballaren a la ciutat, o millor, en els tres centres principals abans esmentats. A aquests cal afegir-hi cinc impresos més realitzats a Barcelona: quatre els canten la capella de la catedral els anys 1736 i 1737, anys que corresponen a un moment d'interinitat en el mestratge de la Seu, entre el mestre Picanyol i el mestre Josep Pujol. ${ }^{4}$ Aquesta interinitat, reflectida en els impresos, és clara -com ho demostra J. Pavia- en les seves recerques documentals: Joseph Picanyol va succeir Valls a la seva jubilació l'any 1726 i el 1736 es trasllada al convent madrileny de Las Descalzas Reales. I Josep Pujol comença el càrrec de mestre l'any 1737 i s'hi està fins a la jubilació l'any 1774. Pujol és el mestre amb més obres ressenyades: 19, sense incloure les quatre anònimes.

\section{Mestres de la catedral}

1. Joan BARTER (Mequinenza5, 1648 - Barcelona, 1706). Va entrar a la Seu Barcelona, procedent de la de Lleida, l'any1682 i s'hi està fins a la seva jubilació l'any 1696. El nostre Catàleg recull nou grups de villancets, que abarquen els anys 1668 ( $\left.\mathrm{n}^{\circ} 254\right), 1690\left(\mathrm{n}^{\circ} 255\right), 1691\left(\mathrm{n}^{\circ}\right.$ 256), 1693 (nn. 257-260) i 1696 (nn. 261 i 262); en total són 28 obres diferents (cada grup conté 4 villancets), cap de les quals no es troba en la llista d'obres que li atorga J. Pavia i que es guarden, amb música, a la Biblioteca de Catalunya procedents de la catedral. ${ }^{6}$ Les festes que hi trobem són les següents: més un $*$.

2. No hi hem inclós, entre les 85 , les quatre obres que en el Catàleg estan ressenyades en l'apèndix $\left(=n^{\circ}\right.$ d'ordre

3. Són els que tenen el $n^{\circ}$ d'ordre 286-291. De l'Oratori de Palma de Mallorca provenen els que a Montserrat provenen del comte d'Aiamans.

4. Cal tenir present que Francesc Valls, ja jubilat, encara escriu i fa cantar uns villancets i un oratori l'any 1736 (nn. 193 i 201), en el llibret dels quals li donen el títol de Mestre de capella.

5. J. Mujal i Elias, Lérida. Historia de la Música, Lleida, 1975, pàg. 106.

6. J. Pavia i Simó, La música a la catedral de Barcelona, Barcelona, 1986, pàg. 231. 
1) L'any 1688 ( $\mathrm{n}^{\circ} 254$ ), per la festa de la Purísima ${ }^{7}$ i la seva octava a la catedral, festa promoguda per la seva Confraria. Barter, per a aquesta festa compon tres villancets, tots tres amb l'estructura formal d' «estribillo» i «coplas». Si bé d'aquestes obres no se n'ha conservat la música, en canvi en tenim altres exemplars impresos a Catalunya.

2) Any 1690 ( $\left.n^{\circ} 255\right)$ en el convent de Sant Josep dels Carmelites Descalços ${ }^{8}$, en motiu de portar el Sagrament al nou altar i instauració de la imatge de la Mare de Déu de la Consolació, la que santa Teresa de Jesús portava en les fundacions que feia. Per a aquesta festa el mestre de capella de la catedral escriu i interpreta quatre villancets, tots també amb la mateixa estructura d' «estribillo» $\mathrm{i}$ «coplas». Hi ha una altra copia duplicada del llibret a l'Arxiu Històric de la Ciutat de Barcelona (AHCB).

3) L'any següent, 1691 ( $n^{\circ} 256$ ), els tres villancets del mestre Barter són per a una festa d'acció de gràcies promoguda pels Majorals del Sant Crist de la Ribera de Sant Joan en el dia de l'exaltació de la Santa Creu (14 de setembre), a l'església de Sant Joan. El motiu fou perquè el barri de la Ribera i altres llocs de la ciutat es van lliurar de l'estrall de les bombes. ${ }^{9} \mathrm{Hi}$ assistiren els Diputats i Oïdors de Comptes de Catalunya. L'estructura dels villancets és: «estribillo» i «coplas» per als tres, però el segon porta una «Introducción».

4) Els dies 5, 6, 7 i 11 d'abril de l'any 1693 (nn. 257-260) els villancets, tots cantats en el convent de la Mercè, estan dedicats a santa Maria de Cervelló o del Socors (Socós, diuen els textos), ${ }^{10}$ en motiu de la canonització, promoguda pel Papa Innocenci XII, d'aquesta religiosa. Cada dia es cantaren tres villancets, tots diferents, però amb la mateixa estructura formal d' «estribillo» i «coplas». De tots els quatre impresos s'en conserven altres còpies.

5) De l'any 1696, any de la jubilació del mestre Barter al mes de desembre, en tenim dos de mostra: un ( $n^{\circ}$ 262) del 20 de maig, al convent de la Mercè pel fet d'haver-se aconseguit que la festa Patronal pogués celebrar-se litúrgicament amb Ritu Doble a tota l'església. ${ }^{11}$ L'altre imprès d'aquest any $\left(n^{\circ} 261\right)$ fa referència al recobrament de la salut del rei d'Espanya Carles segon. ${ }^{12}$ La celebració, promoguda pel Magistrat de la Llotja del Mar, es féu a la Casa de Contractació de Catalunya ${ }^{13}$ el dia 12 de novembre. Els sis villancets, tres per a cada una de les celebracions esmentades, tenen idéntica forma: «estribillo» $\mathrm{i}$ «coplas».

7. En la relació de festes que fem ací no repetim la descripció de l'imprès que ja hem fet en el Catàleg.

8. G. Barraquer I Roviralta, Las casas de religiosos en Cataluña, Barcelona, 1906, no parla d'aquest altar, sí en canvi G. Beltran Larroya, Fuentes históricas de la Provincia O.C.D. de San José (Cataluña y Baleares), Roma, 1986, pàgs 450-451 (doc. $\mathrm{n}^{\circ}$ 88) en què transcriu el contracte per al nou retaule del convent de Sant Josep, obra de Josep Sayós. El contracte és de l'any 1615. A mig segle XVIII se'n va fer un altre que desaparegué l'any 1835 (vegeu: G. BARRAQUER, op. cit., pàg. 446). Per a tenir una idea del que devia ser la festa del trasllat del Sagrament al nou altar -en aquella època, aquest ritu expressava la «inauguració» oficial del mateix per a l'ús litúrgic- podeu veure dos documents a G. BELTRAN LARROYA, op. cit., pàgs. 552 i 553 (doc. $n^{\circ} 123$ ), en què parla del que es féu a Tarragona l'any 1599, i pàgs. 599-604 (doc. n 133) quan es féu la festa al nou convent de «Josepets» de Gràcia l'any 1687.

9. Deu tractar-se del bombardeig de la ciutat, per part dels francesos, dels dies 10 i 11 de juliol d'aquest any. Vegeu: F. Soldevila, Història de Catalunya, vol. III, Barcelona, 1962, pàg. 1090.

10. Nascuda a Barcelona (1230-1290), de la familia noble dels Cervelló, fou fundadora de la branca femenina de l'orde de la Mercè i primera superiora. La canonització es féu l’any 1692. Vegeu: Gran Enciclopèdia Catalana (GEC), «Cervelló, Maria de».

11. El Ritu Doble era la máxima categoría de les festes litúrgiques. Podia ser de primera o de segona classe.

12. Aquest monarca (1661-1700) era de naturalesa malaltissa. A Castella li donaren el sobrenom de El Hechizado, en canvi, era ben reconegut a Catalunya pels seus intents «neoforalistes». Vegeu: GEC, «Carles II d'Espanya».

13. Molt probablemment es tracta de l'edifici de la la Llotja, el qual, inicialment, era el lloc de contractació dels mercaders barcelonins. Vegeu: GEC, «Llotja de Barcelona». 
2. Francesc VALLS (Barcelona?, 1671 - Barcelona, 1747). Va ser proposat com a mestre de la Seu barcelonina, per substituir el jubilat Joan Barter, el desembre de 1696, quan exercia de mestre a Santa Maria del Mar. Les dues obres que ressenyem en el Catàleg (nn. 193 i 201) daten de l'any 1736, quan ja feia deu anys que estava jubilat. Ja hem apuntat abans que Valls, ocasionalment, hauria ocupat el mestratge de la capella musical durant el temps vacant entre Picanyol i Pujol. De fet, com ens notifica Pavia ${ }^{14}$, al moment de la jubilació «el Capítol [catedralici]... li concedí la jubilació, tot demanant-li, sense cap intenció d'agravar-lo, que no deixés de compondre i que, sempre que la Capella el necesités, «portia lo compàs».

1) Els dies 26, 27 i 28 d'agost del 1736 Valls, al front de la capella de música de la Seu, interpretà tres villancets en motiu de la construcció - deu voler dir de la Dedicació- de la nova capella dedicada a l'Esperit Sant i a Maria Font de la Salud, en el carrer Nou de la ciutat. ${ }^{15}$ Els tres villancets per a l'ocasió tenen una estructura formal complexa, a base de recitatius i àries. Es conserven altres duplicats de l'imprès a la Biblioteca de la Universitat.

2) L'altra obra és un oratori, Eco de la Voz divina, en motiu de la festa patronal del Gremi d'argenters de Barcelona, Sant Eloi. Es va interpretar a l'església del convent de la Mercè el dia 1 de desembre de 1736. N'existeixen duplicats a la Biblioteca Nacional de Madrid i a la Biblioteca de la Universitat de Barcelona.

3. Joseph PICANYOL (PICAÑOL) (?, 1700 - Madrid, 1769) ${ }^{16}$. Va ser el sucesor de Valls a la capella de la Seu l'any 1726 i fins aleshores era mestre de la capella del Palau de la Comtessa ${ }^{17}$. Després de deu anys de mestratge a la Seu barcelonina anà a exercir al convent madrileny de Las Descalzas Reales fins a la seva mort ${ }^{18}$. D'ell tenim tres oratoris per a festes $\mathrm{i}$ un conjunt de tres villancets per a professió religiosa:

1) L'any 1731 ( $\left.n^{\circ} 264\right)$ fa cantar al convent de la Mercè un oratori dedicat a sant Serapió, mártir, «Caballero de el R[eal] y Militar Orden de Nuestra Señora de la Merced Redención de Cautivos... en el quarto dia de las fiestas de la Declaración de su Culto immemorial» ${ }^{19}:$ El Macabeo de la Ley de Gracia. Existeixen a Catalunya alguns altres exemplars de l'imprès.

14. La música a la catedral de Barcelona en el segle XVII, Barcelona, 1986, págs. 235-236. Aquest mateix autor a Tonos de Francesc Valls (c. 1671-1747), vol. II, Barcelona, 2001, pàg. 16-17 ens explica efectivament el període de temps que va passar entre el magisteri de Picanyol i el de Pujol, fet que explica els oratoris de Valls en aquest període. A més (pàg. 15), ens assebenta de les males relacions entre Valls i Picanyol, segurament a causa de la divergencia entre austriacistes $\mathrm{i}$ borbons.

15. Arxiu Diocesà de Barcelona (ADB), ms. Gratiarum 1734-1740, fol. 177v: «Licencias la Capella dels Siegos en lo carrer Nou». "Nos Dn. Josephus Ignatius de Amigant et Olzina pbr. [...] pro Illmo. et Rmo Dno, Dn. Philippo de Aguado et Requenxo [...] Episcopus [...] die Sexta Decembris 1732. Causis et rationibus in eis expressis licentia concessione vobis ut in Vico nuncupato novo [...] qandam capellam seu Ecclesiam publicam [...] sine tamen Jurium Parochialium prejudicio construere et aedificare facere possetis [...] Datum Barchinone die 25 Augusti 1736». Va promoure l'obra la Confraria de l'Esperit Sant..

16. GEC, «Picanyol, Joseph».

17. J. PAvia I Simó, Tonos de Francesc Valls (c. 1671-1747), vol. II, Barcelona, 2001, pàg. 14. Vegeu també C. AlCALÁ, «El Palacio de la Condesa y su capilla musical», en Revista de Musicología (1998), pàgs. 206-207.

18. El llibre de P. CAPDEPón, La música en el Monasterio de las Descalzas Reales (siglo XVIII), Madrid, 1999. pàgs. 51-52 parla de Picanyol. La breu biografia que hi posa, extreta del The New Grove Dictionary of Music and Musicians, Londres, 1980, s'ha de revisar totalment.

19. Ha de tractar-se de sant Serapió, religiós mercedari, nascut a Anglaterra i mort màrtir a Alger l'any 1240 . El seu culte, a petició dels bisbes de Barcelona i de Girona, va ser confirmat per la Congregació de Ritus l'any 1728. 
2) L'any 1734 ( $n^{\circ} 192$ ), el dia 12 de maig, amb la capella de la Seu canta tres villancets en la professió religiosa de la senyora Maria Ignàsia de Bergadà i de Taraval en el convent de Santa Magdalena (Agustines). Els villancets són complexos en la seva forma, amb recitatius i àries.

3) El 1735 ( $\left.n^{\circ} 195\right)$, el dia 30 de maig, estrena, segurament a la catedral, l'oratori Judith triunfante, en motiu de la festa a la Immaculada Concepció de Maria, el qual es compon de tres «escenes». N'existeixen diferents duplicats a Catalunya.

4) El dia 14 de juny de l'any $1736\left(n^{\circ} 194\right)^{20}$, per la mateixa celebració de la Purísima, probablement també a la Seu, estrena l'oratori La Valiente Judith, amb tres actes i un càntic final. N'existeixen altres duplicats.

A partir de la seva anada a Madrid, com que el càrrec de mestre queda vacant, la capella de la catedral canta diferents obres: l'oratori que el 21 de maig del 1736 canta a la Immaculada Concepcio de Maria, patrocinat per la seva Congregació, La escogida Esther $\left(\mathrm{n}^{\circ} 196\right),{ }^{21}$ amb tres actes i càntic final. El dia 4 de setembre la capella canta tres villancets ("Poesias lírico-sacras») (n 189) per a la professió religiosa de Maria Ramona Sastre, Font i Marquet, en el convent de la Companyia de Maria. L'any següent, 1737, el dia 31 de maig es canta l'oratori El grande Samuel (nº 210) en el segon dia del tretzenari de Sant Francesc de Paula en el convent dels mínims; obra estructurada en dues parts i càntic final, de la qual n'existeixen diferents còpies impreses a la Biblioteca de la Universitat i el dia 10 de juny la mateixa capella en canta un per la festa de la Puríssima, sense indicar mestre de capella, ja que encara no estava nomenat el sucesor de Picanyol. Es tracta de l'oratori $L a$ privilegiada Esther ( $\mathrm{n}^{\circ} 197$ ), del llibret del qual n'existeixen diversos duplicats a Catalunya.

4. Joseph PUJOL va succeir Picanyol al cap de la capella de la catedral l'agost del 1737 i es va jubilar l'any 1774. D'aquest mestre és del que en la col·lecció d'impresos de Montserrat se n'han conservat més exemplars: divuit ${ }^{22}$ en total, que van des de l'any 1738 fins el 1770 . Per ordre cronològic tenim: 1738: 5; 1739: $1 ; 1740: 5 ; 1757: 1 ; 1758: 3 ; 1763: 1 ; 1766: 1 ; 1770: 1$.

D'aquests, sis obres són conjunts de tres villancets, per tant, en total sumen 36 obres. A més cal notar que en un sol any -1738 i 1740- compon almenys cinc obres d'aquestes característiques cada any.

1) L'any 1738, en el dia 6 de maig, al monestir de Santa Clara ( $\left.n^{\circ} 190\right)$ (Benedictines), tres villancets per a una professió monástica; els dies 22 i 23 del mateix mes, un oratori amb tres actes i «coplas», David triunfante ( ${ }^{\circ}$ 204), en la canonització de sant Francesc de Régis ${ }^{23}$ al col·legi dels jesuïtes ${ }^{24}$ i el dia 26 , un Drama sacre, amb tres escenes i «coplas», per a la Congre-

20. En aquesta data, però, Picanyol ja havia marxat a Madrid a ocupar el càrrec del nou magisteri de Las Descalzas. Possiblement l'obra en qüestió ja la tenia escrita abans de marxar. Vegeu: J. PAVIA, Tonos de Francesc Valls (c. 16711747), vol. II, Barcelona, 2001, pàg. 16.

21. Causa estranyesa la proximitat de dates -21 de maig i 14 de juny-per a la mateixa celebració i dintre del mateix any: sembla com si hi hagués un error, perquè tant el Prefecte com els Majorals de la Congregació són els mateixos, en tot cas, però, ignorem la raó per la qual la Congregació mariana va cantar en dues dates properes dos oratoris diferents el mateix any.

22. El n 183 és repetició del $n^{\circ} 182$.

23. Va néixer a Fontcouberte, entre Narbona i Carcassona, el 31 de gener de 1597. Es va fer jesuita. Gran missioner rural de terres de França, morí el 31 de desembre de 1640. Beatificat per Climent XI el 1716, Climent XII el va canonitzar el 1737.

24. Deu tractar-se del col·legi de Cordelles, situat prop de l’església de Betlem. Vegeu article: «Cordelles, col·legi de» a GEC. 
gació mariana: La Reparadora del linaje humano ( $\mathrm{n}^{\circ}$ 198), a la catedral. Encara el 30 d'agost, a Vilafranca del Penedès, tres villancets en la festa patronal de Sant Fèlix (n $\left.{ }^{\circ} 170\right)^{25}$. La darrera obra d'aquest any, l'oratori El mejor ajuste (nn. 212 i 213), no indica ni dia ni mes, però amb tota probabilitat, degut al tema de l'Expectació del part de la Verge Maria, va tenir lloc el mes de desembre, durant l'Advent: era la festa dels Corredors de Canvi ${ }^{26}$. La festa religiosa es va celebrar al convent de la Mercè. Aquest oratori inclou dos villancets.

2) De l'any 1739 (nn. 182 i 183, ambdós són un duplicat de la mateixa festa) tenim un conjunt de tres villancets de Professió monástica el dia 16 de desembre: dues germanes, Maria Francesca i Teresa de Palau i Magarola, en el convent de Sant Joan Baptista, de l'orde d'aquest mateix nom.

3) L'any 1740 torna a ser ric d'obres d'aquest compositor: cinc obres ens aporta el Catàleg: el dia 20 d'abril, tres villancets al monestir de Mont Sió (Dominiques), per a la Professió i Velació de $\mathrm{M}^{\mathrm{a}}$ Teresa d'Alòs i Fontaner $\left(\mathrm{n}^{\circ} 186\right)$; les tres obres són complexes en la seva estructura formal. El dia 6 de juny, a la catedral, l'oratori La esforzada Jaél ( $n^{\circ} 199$ ), en tres actes i càntic final, per a la festa de la Congregació mariana. El dia 13 del mateix mes, al monestir de Sant Antoni i Santa Clara (Benedictines), tres villancets per a la professió solemne de Catalina de Cartellà, Çabastida i de Llupià ( $\left.n^{\circ} 191\right)$; tots tres ben complexos de forma. El 30 de juny i 1 de juliol, oratori en dos actes i càntic Luz soberana del entendimiento ( $n^{\circ} 208$ ), en la festa de sant Tomàs d'Aquino al col·legi o seminari tridentí de Montalegre. La darrera obra de l'any, de l'11 d'octubre, són tres villancets $\left(n^{\circ} 187\right)$ en la Professió de Jerónima Trinxet al convent dels Àngels (Dominiques); els tres villancets tenen una estructura formal complexa.

4) De l'any 1757 només tenim un oratori, La Vara de Dios ( $\mathrm{n}^{\circ} 231$ ), per al novenari de sant Vicenç Ferrer, en el convent dominicà de Santa Caterina. Es cantà el dia 17 d'abril. N'existeix un altre exemplar al fons Bonsoms de la Biblioteca de Catalunya.

5) L'any 1758 ens proporciona tres oratoris:

El dia 15 de maig, Abigail ( $n^{\circ}$ 5): és un drama sacre en motiu de la festa de la Congregació mariana a l'església de Betlem, dels PP. Jesuïtes; consta de tres actes i un càntic final. N'hi ha altres duplicats a Barcelona.

El dia 16 de juliol, al convent del Carmel, es cantà El triunfo de Elias (n² 236), drama sacre en motiu de la festa de la Mare de Déu del Carme i el del seu novenari. L'obra és tota segui$\mathrm{da}$, sense actes ni escenes. N'existeixen dues còpies més a Barcelona.

El segon diumenge d'octubre ${ }^{27}$, en motiu del novenari de la Mare de Déu del Remei, al convent dels Trinitaris, es cantà l'oratori Ensayo lírico sobre el Psalmo 46 Omnes Gentes plaudite $\left(\mathrm{n}^{\circ} 234\right)$. L'obra és tota seguida. N'existeixen altres duplicats a Barcelona.

25. J. Pavia, Tonos de Francesc Valls (c. 1671-1747), vol. II, Barcelona. 2001, pàg. 18, parla d'una anada de Pujol. aquell any, a Vilafranca, amb alguns músics, el dia 25 d'agost, vigílies de Sant Fèlix.

26. Anomenats també «Corredors d'orella» o «de llotja» eren els agents gremiats de compra-venda de productes d’importació i exportació, els qui intervenien en la negociació de lletres de canvi, contractació d’assegurances, etc. Pertanyien, en certa manera, al gremi dels mercaders (GEC).

27. Devia ser el dia 8 del mes. 
6) De l'any 1763, per la festa de la Mare de Déu del Carme (16 de juliol), coneixem el «Drama músico» Iris de Paz del Carmelo ( ${ }^{\circ} 237$ ), cantat a l'església del convent dels Carmelites calçats. L'obra és seguida, sense distinció de parts. N'existeix un altre duplicat a l'AHCB.

7) Un drame sacre: La exaltación de Simón (n 238), de l'any 1766, pels dies 19 i 21 d'octubre al convent dels Trinitaris calçats, en motiu de la beatificació de Simó de Rojas. ${ }^{28}$ L'obra està dividida en tres actes.

8) L'any 1770, el 27 de maig, a l'església de Sant Sebastià es cantà l'oratori El zelo de la Casa de Dios ( ${ }^{\circ} 277$ ), dedicat al beat Francesc Caracciolo. ${ }^{29}$ L'oratori és seguit, sense parts, amb un càntic final. Existeixen altres exemplars impresos a la Biblioteca de la Universitat.

5. Francesc QUERALT (Les Borges Blanques, 1740 - Barcelona, 1825). Va succeir Joseph Pujol al capdevant de la capella de la Seu l'any 1774 i exercí el càrrec fins a la seva jubilació l'any 1815. En el Catàleg s'hi ressenyen vuit obres, algunes sense data.

1) L'any 1775 , en motiu de la inauguració del nou temple -l'actual- del convent de la Mercè $^{30}$ el dia 1 de setembre, Queralt, encara clergue, fa cantar l'oratori La translación del Arca ( $\left.{ }^{\circ} 276\right)$, el qual, a més del cos general de l'oratori, té una «Licencia» cantada pel cor i un càntic final. N'existeixen dos altres exemplars a Barcelona.

2) Els dies 5 i 6 de setembre de 1779, en el convent dels Trinitaris calçats, la capella de la Seu cantà l'oratori Josué triunfante de Amalec ( $\mathrm{n}^{\circ} 243$ ), en motiu de la beatificació de Miquel dels Sants. ${ }^{31}$ Un fet curiós que trobem en la portada del llibret imprès és que els dos dies següents, el 7 i el 8, va cantar el mateix oratori la capella de música del Palau, amb el mestre Josep Duran al davant, per tant amb música d'aquest segurament. A Barcelona trobem dues altres còpies del llibret imprès.

3) L'any 1784, al convent dels Caputxins, Queralt fa interpretar l'oratori Jerusalen liberada de los Asirios ( $n^{\circ} 278$ ) en motiu de la beatificació de Llorenç de Brindisi. ${ }^{32}$ En l'estructura formal de la peça hi trobem el cos de l'oratori, un quartet vocal i, com a final, un Cor d'Hebreus.

4) Una nova beatificació, en aquest cas del religiós mínim Gaspar de Bono ${ }^{33}$ fou el motiu d'un nou oratori, Jeremias glorioso después de la muerte ( $\left.{ }^{\circ} 245\right)$, en el convent de l'orde els dies 5 , 6 i 7 de juliol de 1787. Oratori seguit. Trobem una altra copia impresa a la Biblioteca de Catalunya.

\footnotetext{
28. Religiós trinitari, predicador de renom i confesor de la reina Isabel de Borbó. Morí a Madrid l'any 1624. Fou beatificat pel papa Benet XIV l'any 1766.

29. Nascut a Vila Santa Maria (Italia) l'any 1563, sacerdot, fundà l'orde dels Clergues Regulars Menors (CC. RR. MM.). Morí l'any 1608. Fou beatificat per Climent XIV el 4 de juny de 1769 i canonitzat més tard per Pius VII el 24 de maig de 1807.

30. G. Barraquer i Roviralta, Las casas de religiosos en Cataluña, II, Barcelona, 1906, pàg. 105: “...a 25 de abril de 1765 el Marqués de la Mina, Capitán General de Cataluña, puso como delegado del Rey la primera piedra del templo actual, cuya construcción duró diez años, siendo bendecido en 9 de septiembre de 1775».

31. Religiós Trinitari, nasqué a Vic el 29 de setembre de 1591. Morí a Valladolid el 10 d'abril de 1625 . Pius VI el beatificà el 2 de maig de 1779. Fou canonitzat per Pius IX el 8 de maig de 1862. La seva festa se celebra el dia aniversari de la seva mort.

32. Nascut a Brindisi (Itàlia) l'any 1559, es féu caputxí. Morí a Lisboa el 22 de juliol de 1619. Va ser beatificat per Pius VI l'any 1783 i canonitzat per Lleó XIII l'any 1881.

33. Nascut a Valencia el 1530, es féu religiós Mínim. Morí a la seva ciutat el 1604. Pius VI el beatificà l’any 1786.
} 
5) A partir del nº 286 fins el 289 inclusius tenim oratoris de Francesc Queralt per a les funcions celebrades a l'oratori de Sant Felip Neri de Barcelona, anomenades -almenys en època recent- «oratori vespertí». ${ }^{34}$ L'obra musical, el text de la qual tenia un caire alegòrico-moral, incloïa una prèdica de mitja hora a la meitat de la peça. Els impresos d'aquestes obres normalment no portaven una data concreta, sinó que s'hi posava a mà perquè l'obra es repetia diferents vegades. D'aquests quatre oratoris de Queralt només els nn. 286 i 287 porten data d'impressió del llibret a la portada el $n^{\circ} 286$ és de l'any 1781 i el 287 porta impresa també la data d'interpretació: el 16 de febrer de 1790. El text de l'oratori no 286 va ser interpretat ja a Sant Felip Neri els anys 1772 i 1774 (reimpressió del llibret), amb música del mestre Joseph Pujol. ${ }^{35}$ Els titols dels quatre oratoris són: $\mathrm{n}^{\circ}$ 286: La muerte del pecador, drama sacre; $\mathrm{n}^{\circ}$ 287: El Juicio particular ${ }^{36}$, drama sacre; $\mathrm{n}^{\circ}$ 288: La resurrección de Lázaro, drama sacre i n 289: La muerte de Abel, drama sacre. Tots aquests, com ja s'ha dit, formen part del llegat Josep $\mathrm{M}^{\mathrm{a}}$ Casacoberta de la Biblioteca de Montserrat.

6. Ramon ALEIX i BATLLE (Barcelona, 1784 - 1850). Va succeir Queralt en el mestratge de la capella de la Seu el $1715 .{ }^{37}$ En el Catàleg només li coneixem un drama sacre per a l'oratori de Sant Felip Neri La Pasion de Jesu-Christo. El llibret imprès no porta data, però Carrera i Bulbena (pàg. 144) diu que el manuscrit musical és de l'any 1817. L'imprès, com els anteriors, és del llegat Josep $\mathrm{M}^{\mathrm{a}}$ de Casacoberta.

\section{II}

\section{Mestres de Santa Maria del Mar}

1. Jaume de CASELLAS (Valls, ca. 1690 - Toledo, 1764). Mestre de Granollers (1714), de Santa Maria del Mar (1715) i després, definitivament, de la catedral de Toledo (1736-1762). ${ }^{38}$ Del període de Santa Maria del Mar el Catàleg esmenta dos conjunts d'obres, ambdues del mateix any 1729:

1) El dia 26 de juny estrena tres villancets ( $\left.n^{\circ} 180\right)$ per a la Professió monàstica de sor Maria Gertrudis Mollar i Roig en el convent de les Terciàries Franciscanes de Santa Elisabet.

34. Per al tema d'aquestes celebracions a Sant Felip Neri vegeu: Josep de C. Laplana, L'oratori de sant Felip Neri de Barcelona i el seu patrimoni artístic $i$ monumental, Publicacions de l'Abadia de Montserrat, 1978, pàgs. 137ss, el qual ho extreu bàsicament del llibre J. CARRERAS I Bulbena, El Oratorio Musical desde sus origenes hasta nuestros días, Barcelona, 1906, pàgs. 135ss, i dels Apunts diversos del P. Agustí Mas, conservats a l'arxiu de la casa. Fins l'any 1936, s'hi conservava la música escrita d'aquests oratoris.

35. Segons consta en el registre del fons Bonsoms de la Biblioteca de Catalunya: F. Bon 1253 i 1256 respectivament.

36. Coneixem una portada igual de l'any 1777 d'impresos a la Biblioteca Pública Episcopal de Barcelona i al fons Bonsoms (tres exemplars).

37. La nota biogràfica de la GEC («Aleix i Batlle, Ramon») només diu que va ser mestre de capella de Santa Maria del Mar. Aleix va ser nomenat mestre de Santa Maria del Mar l'any 1819 i a la catedral el va succeir Josep Rosés. Vegeu: J. Pavia I Simó, "Documents per a la història de les capelles de música de Barcelona. aa. 1763-1820", en Anuario Musical, XXXVII (1983), pàg. 126.

38. GEC, «Caselles, Jaume de». Per a les dades dels mestres d'aquesta capella vegeu: F. BALDelló, "La música en la Basílica Parroquial de Santa María del Mar, de Barcelona (Notas históricas)”, en Anuario Musical XVII (1962), pàgs. 220-226. 
L'estructura dels villancets ja és complexa amb recitatius i àries. S'en coneix una altra còpia impresa a la Biblioteca de la Universitat de Barcelona.

2) Sense data, només amb la de l'any 1729, estrena un oratori La igual justicia de Dios ( $n^{\circ} 263$ ) en el convent dels Caputxins, en motiu de la beatificació de Fidel de Sigmaringa. ${ }^{39}$ L'obra és tota seguida composta només de recitatius i àries. Altres impresos a Barcelona i Ripoll.

2. Salvador FIGUERA ${ }^{40}$ és l'altre mestre, per successió cronològica, de Santa Maria del Mar, en desconeixem, però, les dades biogràfiques; va ser el successor de Casellas ${ }^{41}$ l'any 1734. D'aquest mestre tenim en el Catàleg el major nombre d'obres impreses dels mestres d'aquesta parroquial important de Barcelona: 11 en total.

1) L'any 1736 , el dia 8 d'abril, estrena tres villancets ( $\left.n^{\circ} 188\right)$ per a la Professió monàstica de Sor Maria Teresa Llauder i Duran en el convent franciscà de nostra Senyora de Jerusalem. Els tres villancets tenen una estructura formal a base de recitatius i àries.

2) L'any següent, 1737, ens proporciona tres conjunts d'obres: el dia 30 de juny, per a la festa de Sant Antoni de Pàdua, tres villancets en el convent de Sant Francesc ( $\mathrm{n}^{\circ} 172$ ), d'estructura formal complexa; els dies 29, 30 i 31 de desembre tres villancets ( $n^{\circ} 202$ ) i l'oratori Las dos Sillas del Empyreo ( $\mathrm{n}^{\circ}$ 203) amb motiu de les festes de beatificació de Josep de Leonissa i Serafí de Montegranaro ${ }^{42}$, en el convent dels Caputxins. Els villancets tenen una estructura complexa, com correspon a l'època, l'oratori és tot seguit. Coneixem altres exemplars impresos de l'oratori a diferents biblioteques de Barcelona.

3) L'any 1738, pels dies 13 i 14 d'abril, fa cantar l'Oratorio a el mas fuerte escudo de la Iglesia Santo Thomás de Aquino ( ${ }^{\circ} 206$ ) al col·legi dels Clergues Menors, Casa de Sant Sebastià. L'oratori és seguit, sense parts. I el 13 de juny, tres villancets $\left(n^{\circ} 173\right)$ per a la festa de Sant Antoni de Pàdua en el convent de Sant Francesc. D'aquesta darrera obra n'hi ha un altre exemplar imprès a la Biblioteca Nacional de Madrid.

4) L'any 1739, per a la festa també de Sant Antoni de Pàdua, 13 de juny, compon l'Oratorio armonico $\left(\mathrm{n}^{\circ} 174\right)$, per al convent dels franciscans. L'obra es divideix en dos «actes». N'hi ha duplicats a Madrid i a Barcelona.

5) L'any 1740, els dies 8 i 9 de maig, a la Casa de Sant Sebastià dels Clergues Menors Regulars, interpreta l'oratori Sacros Armoniosos Ecos (n²07) en honor de sant Tomàs d'Aqui-

39. Marc Rey, Fidel en entrar al noviciat dels caputxins, nasqué el 1577 a Sigmaringen, Principat de Hohenzollern. Religiós molt observant i auster va morir màrtir de mans dels protestants suïssos el 24 d'abril de 1622 . El Papa Benet XIII el beatificà l'any $1729 \mathrm{i}$ Benet XIV el canonitzà l'any 1743.

40. La GEC li dóna el cognom «FIGUERES».

41. Interinament hi hagué Pau Genís (vegeu: F. BALDELló, op. cit., pàg. 224). Baldelló deu fer una confusió o un error de transcripció del nom quan indica, sense més, el nomenament d'un tal Salvador «CAPELLA» l'any $1734 \mathrm{i}$, en canvi, posa el nomenament de Figuera l'any 1743, quan els nostres impresos, de fet, ens diuen que era mestre ja el 1736: aquest «Capella» ha de ser, amb tota seguretat, FIGUERA i s' ha de canviar la data de 1743 en el nomenament de Figuera per la de 1734.

42. Josep de Leonissa nasqué a aquest lloc (Itàlia) l'any 1556. Es féu caputxí. Morí l'any1612. Va ser beatificat l'any 1737 per Climent XII i canonitzat per Benet XIV l'any 1746. Serafí, nascut a Montegranaro (Itàlia) l'any 1540 es féu germà lleg caputxí. Morí a Ascoli el 1604. El Papa Benet XIII l'any 1728 n'aprovà el trasllat de les relíquies i el culte i el 1767 Climent XIII el canonitzà. El nostre imprès, però, sembla que indiqui que els dos frares caputxins van ser beatificats a la vegada, fet que no està indicat en la font hagiogràfica que utilizem: Vie des Saints et des Bienhereux... par les bénédictins de Paris, Tome X, octobre, Paris, 1952, pàg. 401. 
no. L'obra és seguida, a base de recitatius, àries i cors. El dia 26 de juny, festa de Sant Antoni de Pàdua, al convent de Sant Francesc estrena l'oratori El portentoso Moysès ( $\left.\mathrm{n}^{\circ} 175\right)$. L'obra és tota seguida. I encara el 18 de desembre, Mare de Déu de l'Esperança i festa patronal dels Corredors de Canvi, interpreta l'oratori La esperanza más dichosa ( $\mathrm{n}^{\circ} 213$ ), obra amb dos actes i càntic final. D'aquest imprès n'hi ha un duplicat a la Biblioteca Central de Terrassa.

6) Per la festa de Sant Francesc de Paula, al convent dels Mínims, de l'any 1745, interpreta l'oratori Elías en la Corte ( ${ }^{\circ} 223$ ). Obra tota seguida. N'hi ha altres duplicats a Madrid, Terrassa i Barcelona.

3. Pau MONSERRAT (? - Barcelona, 1759). Ocupà el càrrec en substitució de Salvador Figuera al moment de la renúncia d'aquest.

1) Els dies 30 d'abril i 1-2 de maig de l'any 1747 interpretà l'oratori Triumfphos de la Cruz (n $\left.{ }^{\circ} 225\right)$ a la capella dels pares Agonitzants ${ }^{43}$, en celebració de la canonització de sant Camil de Lel·lis. ${ }^{44}$ L'obra és tota seguida. Altres duplicats a Madrid, Barcelona i Terrassa.

Els dies 31 de desembre de 1747 i 1-3 de gener de 1748, en motiu de la canonització de sant Fidel de Sigmaringa i de sant Josep de Leonissa ${ }^{45}$, al convent dels Caputxins, s'interpretà l'oratori La igual Justicia de Dios $\left(\mathrm{n}^{\circ} 226\right)$. Obra tota seguida. Altres duplicats de l'imprès a Barcelona i Terrassa.

2) El 24 de stembre de 1752, festa de la Mercè, té lloc el drama sacre La nube del Tabor $\left(n^{\circ} 228\right)$ en el convent dels mercedaris. L'obra acaba amb un càntic que és la traducció castellana de l'himne Ave maris Stella. ${ }^{46}$ Altres duplicats a Barcelona i Terrassa.

3) Durant el novenari de la Mercè, el dia 27 de setmebre de l'any 1755, té lloc l'oratori $E l$ descenso de la Arca en el Jordán ( $\mathrm{n}^{\circ} 230$ ). L'obra acaba amb un càntic. Altres duplicats a Barcelona.

4) El 25 de juny de 1758, al monestir de monges cistercenques de Valldonzella, es canta el drama al·legòric sacre La piadosa Abigail ( $\mathrm{n}^{\circ} 235$ ), en honor de santa Ludgarda, religiosa cistercenca del segle XIII, encomanat per la seva Confraria de Barcelona. L'obra es divideix en tres actes. Dos altres duplicats a la Biblioteca de Catalunya.

4. Pere Antoni MONLLEÓ (? - Barcelona, 1792), va succeir Pau Monserrat després de guanyar les oposicions, l'any 1759.

1) El 20 d'octubre de l'any 1766, en motiu de la beatificació de Simó de Rojas ${ }^{47}$ que va tenir lloc aquell mateix any, al convent dels Trinitaris calçats, interpretà el drama sacre Joseph exaltado (n² 239). L'obra està dividida en dos actes i una llicència al final.

\footnotetext{
43. Religiosos, fundats per sant Camil de Lel-lis, dedicats a confortar els moribunts.

44. Va néixer prop de Nàpols el 1550. Va fundar l'orde religiós dels Germans dels malalts (Camils o Agonitzants). Morí a Roma el 1614. Va ser beatificat per Benet XIV l'any 1742 i canonitzat el 1746.

45. Fidel va ser canonitzat l'any 1743 i Josep el 1746.

46. El text llatí del qual està imprès al costat de la traducció, en el marge del llibret.

47. Vegeu nota 28.
} 
2) L'any 1770 ens reporta dues obres de Monlleó: el 28 d'agost, en motiu de la festa de Sant Julià, patró dels mercers i dels venedors de teles, en el convent de Sant Gaietà dels Clergues Regulars, interpretà el drama sacre Premio de la caridad ( $\left.{ }^{\circ} 240\right)$. L'obra és tota seguida. I el dia 18 de desembre, per la festa de la patrona dels Corredors de Canvi de Barcelona, la Mare de Déu de l'Esperança, fa cantar l'oratori El prodigio más grande (nº 241 ), obra tota seguida. Un duplicat es troba a l'AHCB.

3) L'any 1782, els dies 3, 4, 5 i 6 de juny, en la preparació de la festa de la inauguració del nou altar major de santa Maria del Mar que tingué lloc el dia 11 següent, amb la col·locació de la Reserva del Santíssim Sagrament al nou sagrari, interpretà el drama músic El gozo del Pueblo de Israel ( $\left.\mathrm{n}^{\circ} 244\right)$, obra dividida en dues parts. Altres duplicats a Barcelona.

4) L'11 de maig de 1784, en les festes en motiu de la beatificació de Llorenç de Brindi$\mathrm{si}^{48}$ pel papa Pius VI, en el convent dels Caputxins, interpretà l'oratori El más glorioso triunfo de Moysés ( $\mathrm{n}^{\circ}$ 279). L'obra acaba amb una llicència i unes «coplas». Un duplicat al fons Bonsoms de la Biblioteca de Catalunya.

5) El 8 de juny de 1787, durant les festes en motiu de la beatificació de Nicolau de Longobardi $^{49}$ en el convent dels Mínims, compongué el drama David festivo (nº 246). L'obra està dividia en tres actes i llicència. Un altre duplicat al fons Bonsoms de la Biblioteca de Catalunya.

5. Francesc ANDREVÍ (Sanaüja, 1786 - Barcelona, 1853). L'any 1814 Andreví guanya les oposicions al magisteri de santa Maria quan en aquell moment era mestre de la catedral de Sogorb; a Barcelona s'hi estigué fins el 1819 i va ser substituït per Ramon Aleix. ${ }^{50}$ D'ell, durant el període de santa Maria del Mar, tenim l'imprès d'un drama sacre La dulzura de la Virtud ( $n^{\circ} 290$ ), per a l'oratori de Sant Felip Neri. No porta data i és tot seguit.

\section{III}

\section{El Palau de la Comtessa ${ }^{51}$}

D'aquest altre centre important de la ciutat només tenim ressenayts dos mestres en el Catàleg:

1. Bernat TRIA (? - Barcelona, 1754).Va començar a exercir a la capella del Palau, en substitució de Josep Picanyol, l'any 1726 i provenia de l'església de Sant Just i Sant Pastor.

1) El 24 de març de 1730 fa cantar l'Oratorio músico en loor, y obsequio de los Dolores de Maria Santissima ( $\mathrm{n}^{\circ}$ 167), en la festa promoguda per la Congragació de senyores. Obra tota seguida. N'hi ha un altre duplicat a la Biblioteca de la Universitat.

48. Vegeu nota 32.

49. Va néixer a Longobardi (Itàlia) el 1649, entrà en l'orde dels Mínims de Sant Francesc de Paula. Morí el 1709. Fou beatificat per Pius VI l'any 1786.

50. F. BaldElló, op. cit., pàg. 225.

51. Per a la informació musical vegeu: C. AlCalà, op. cit., pàgs. 197-214. 
2) El 21 de juny de 1735, en el convent de dominiques de Mont Sió, tres villancets $\left(\mathrm{n}^{\circ}\right.$ 184) per a la Professió religiosa d'Antònia Moreno i Vidal. Trobem dos altres duplicats a la Biblioteca de la Universitat.

3) El dia 18 de febrer de 1736, en el mateix convent de dominiques, tres villancets $\left(n^{\circ} 186\right)$ per a la Professió religiosa de les dues germanes Maria i Francesca de Soler i Bòria. Es troba un duplicat a la Biblioteca Nacional de Madrid.

4) El dia 31 d'agost de 1738, en el convent de Santa Elisabet, per a la Professió de sor Isabel Martí i Buscà, franciscana, interpreta tres villancets «descripción alegorica del afàn amoroso de una Nave...» ( $\mathrm{n}^{\circ} 181$ ). Hi havia un altre duplicat a l'AHCB, però actualment ha desaparegut.

5) El dia 28 de maig de 1747 es canta, al convent dels Trinitaris Descalços l'oratori $E l$ Arca de Dios, colocada en el nuevo Templo de Salomón ( $\left.\mathrm{n}^{\circ} 224\right)$, amb motiu de l'entronització del Sagrament al nou altar major del convent ${ }^{52}$. L'obra musical acaba amb un Himne. Hi ha altres duplicats a Catalunya.

2. Josep DURAN (? - Barcelona, 1791). Fou nomenat mestre del palau, a la mort de Tria, l'any 1754 mentre encara era a Nàpols, però, per desavinences, no començà l'exercici del càrrec fins dos anys més tard. Es va jubilar el 1780 i es diu que, a partir d'aquesta data fins a al seva mort (1791) va exercir de mestre a la catedral, però això no està documentat i, a més, a la Seu, la plaça estava ja coberta per Francesc Queralt.

1. A partir del 27 de març de 1758 i durant tres dies consecutius es fan les festes d'inauguració del nou temple dels Agustins de Barcelona. ${ }^{53}$ En motiu d'aquesta celebració Duran hi estrena l'oratori Arca de Dios (n² 232), amb tres actes i un càntic. Hi ha altres duplicats a Barcelona i a Madrid.

2) Els dies 7 i 8 de setembre de 1779, l'oratori Josué triumfante de Amalec ( $\mathrm{n}^{\circ} 243$ ) celebra la beatificació del religiós Trinitari català Miquel dels $\mathrm{Sants}^{54}$, en el convent dels Trinitaris Descalços. El fet a notar és que el mateix llibret i per a la mateixa festa, però dos dies abans (el 5 i ei 6) va servir per a un oratori del mestre F. Queralt. No sabem si cada mestre hi posà musica a tot el text i cada un el féu interpretar en els dies assenyalats (és la possibilitat més plausible), o que es repartissin la feina, fent-ne una part cada un: això és poc probable ja que l'estructura formal de l'obra no té parts o actes dramàtics.

Una darrera obra barcelonina, anònima, és el drama sacre que l'any 1740 «cantóse en los solemnes, y festivos Cultos, que a tan soberana Patrona (santa Cecilia) tributan en la Iglesia de Nuestra Señora del Carmen sus Devotos los Musicos, y Maestros de Danzar» el dia 22 de novembre. L'obra ( $\left.\mathrm{n}^{\circ} 214\right)$ es titula Troba a un Oratorio italiano. Daniel libre del lago de los leones. Està estructurat en dues parts. En coneixem un duplicat a Terrassa.

52. G. Barraquer i Roviralta, Las casas de religiosos en Cataluña, II, Barcelona, 1906, només parla dels altars posterios que hi hagué en el convent.

53. Es tracta de l'església actual de Sant Agustí, al Raval. Vegeu: G. Barraquer i Roviralta, Las casas de religiosos en Cataluña, II, Barcelona, 1906, pàg. 184 i ss. L'any 1750 la comunitat es trasllada al nou convent; en aquell moment l'església s'estava acabant.

54. Vegeu nota 28. 
Aquest és l'elenc de les obres, majoritàriament desconegudes, que es van compondre i interpretar a Barcelona. És una mostra de la utilitat del Catàleg, ja que, a més, serveix per precisar alguns punts històrics foscos o poc estudiats i corregir els erronis de les principals capelles de música de Barcelona i llurs mestres.

\section{APÈNDIX}

\section{Índex Cronològic}

\begin{tabular}{|c|c|c|c|c|}
\hline data & autor & lloc & festa & $n^{0}$ ordre \\
\hline 1688 & Joan BARTER & Catedral & Immaculada & 254 \\
\hline 1690 & Joan BARTER & Carmelites descalços & Dedicació altar & 255 \\
\hline 1691 & Joan BARTER & Sant Joan & Acció de gràcies & 256 \\
\hline 1693 & Joan BARTER & La Mercè & Santa Maria de Cervelló 257,258 , & 259,260 \\
\hline 1696 & Joan BARTER & Casa de Contractació & Rei Carles II & 261 \\
\hline 1696 & Joan BARTER & La Mercè & Ofici litúrgic & 262 \\
\hline 1729 & Jaume CASELLAS & Convent de santa Elisabet & Professió monàstica & 180 \\
\hline 1729 & Jaume CASELLAS & Caputxins & Beat Fidel de Sigmaringen & 263 \\
\hline 1730 & Bernat TRIA & Palau & M. de Déu dels Dolors & 167 \\
\hline 1731 & Joseph PICANYOL & Caputxins & Beat Fidel de Sigmaringen & 264 \\
\hline 1734 & Joseph PICANYOL & Agustines & Professió monàstica & 192 \\
\hline 1734 & Joseph PICANYOL & Catedral? & Immaculada & 194 \\
\hline 1735 & Bernat TRIA & Dominiques de Mont Sió & Professió monàstica & 184 \\
\hline 1735 & Joseph PICANYOL & Catedral? & Immaculada & 195 \\
\hline 1736 & Bernat TRIA & Dominiques de Mont Sió & Professió monàstica & 185 \\
\hline 1736 & Salvador FIGUERA & Franciscanes de N. Sr ${ }^{a}$ de Jerusalem & Professió religiosa & 188 \\
\hline 1736 & & Companyia de Maria & Professió religiosa & 189 \\
\hline 1736 & Francesc VALLS & Capella Esperit Sant & Inauguració temple & 193 \\
\hline 1736 & & Catedral? & Immaculada & 196 \\
\hline 1736 & Francesc VALLS & La Mercè & Sant Eloi & 201 \\
\hline 1737 & Salvador FIGUERA & Convent de Sant Francesc & Sant Antoni de Pàdua & 172 \\
\hline 1737 & & Catedral? & Immaculada & 197 \\
\hline \multirow[t]{2}{*}{1737} & Salvador FIGUERA & Caputxins & Beatificació de Josep de Leonissa & \\
\hline & & & i Serafí de Montegranaro & 202,203 \\
\hline 1737 & & Mínims & Sant Francesc de Paula & 210 \\
\hline 1738 & Salvador FIGUERA & Convent de Sant Francesc & Sant Antoni de Pàdua & 173 \\
\hline 1738 & Bernat TRIA & Convent de Santa Elisabet & Professió monàstica & 181 \\
\hline 1738 & Joseph PUJOL & Benedictines de Santa Clara & Professió monàstica & 190 \\
\hline 1738 & Joseph PUJOL & Catedral? & Immaculada & 198 \\
\hline 1738 & Joseph PUJOL & Col·legi dels jesuïtes & Canonització de Francesc de Régis & 204 \\
\hline 1738 & Bernat TRIA & Col·legi dels jesuïtes (Betlem) & Canonització de Francesc de Régis & 205 \\
\hline
\end{tabular}




\begin{tabular}{|c|c|c|c|c|}
\hline 1738 & Salvador FIGUERA & Clergues Menors (Sant Sebastià) & Sant Tomàs d'Aquino & 206 \\
\hline 1739 & Salvador FIGUERA & Convent de Sant Francesc & Sant Antoni de Pàdua & 174 \\
\hline 1739 & Joseph PUJOL & Sant Joan Baptista & Professió monàstica & 182,183 \\
\hline 1740 & Salvador FIGUERA & Convent de Sant Francesc & Sant Antoni de Pàdua & 175 \\
\hline 1740 & Joseph PUJOL & Dominiques de Mont Sió & Professió monàstica & 186 \\
\hline 1740 & Joseph PUJOL & Dominiques del convent dels Àngels & Professió monàstica & 187 \\
\hline 1740 & Joseph PUJOL & Benedictines de Santa Clara & Professió monàstica & 191 \\
\hline 1740 & Joseph PUJOL & Catedral? & Immaculada & 199 \\
\hline 1740 & Salvador FIGUERA & Clergues Menors & Sant Tomàs d'Aquino & 207 \\
\hline 1740 & Joseph PUJOL & Col·legi de Montalegre & Sant Tomàs d'Aquino & 208 \\
\hline 1740 & Salvador FIGUERA & La Mercè & Corredors de Canvi & 213 \\
\hline 1740 & & Convent del Carme & Santa Cecília & 214 \\
\hline 1742 & Bernat TRIA & Agonitzants & Beatificació de Camil de Lel·lis & 222 \\
\hline 1745 & Salvador FIGUERA & Mínims & Sant Francesc de Paula & 223 \\
\hline 1747 & Bernat TRIA & Trinitaris descalços & Altar major & 224 \\
\hline 1747 & Pau MONSERRAT & Agonitzants & Canonització de Camil de Lel-lis & 225 \\
\hline 1747 & Pau MONSERRAT & Caputxins & $\begin{array}{l}\text { Canonització de Fidel de Sigma- } \\
\text { ringen i de Josep de Leonissa }\end{array}$ & 226 \\
\hline 1750 & Bernat TRIA & Agustins & Dedicació església & 227 \\
\hline 1752 & Pau MONTSERRAT & La Mercè & Festa patronal & 228 \\
\hline 1753 & Bernat TRIA & Valldonzella & Sant Bernat & 229 \\
\hline 1753 & Joseph PUJOL & & Sant Vicenç Ferrer & 282 \\
\hline 1755 & Pau MONSERRAT & La Mercè & Novenari & 230 \\
\hline 1757 & Joseph PUJOL & Santa Caterina & Novenari de Sant Vicenç Ferrer & 231 \\
\hline 1758 & Joseph PUJOL & Betlem & Immaculada & 5 \\
\hline 1758 & Joseph DURAN & Agustins & Església nova & 232,233 \\
\hline 1758 & Joseph PUJOL & Trinitaris & Novenari Mare de Déu del Remei & 234 \\
\hline 1758 & Pau MONSERRAT & Valldonzella & Santa Lutgarda & 235 \\
\hline 1758 & Joseph PUJOL & Carmel & Mare de Déu del Carme & 236 \\
\hline 1763 & Joseph PUJOL & Carmelites calçats & Mare de Déu del Carme & 237 \\
\hline 1766 & Joseph PUJOL & Trinitaris calçats & Beat Simó de Rojas & 238 \\
\hline 1766 & Pere Antoni MONLLEÓ & Trinitaris calçats & Beat Simó de Rojas & 239 \\
\hline 1770 & Pere Antoni MONLLEÓ & Sant Gaietà & Sant Julià & 240 \\
\hline 1770 & Pere Antoni MONLLEÓ & Santa Maria del Mar & Expectació de Maria & 241 \\
\hline 1770 & Joseph PUJOL & Sant Sebastià & Beat Francesc Caracciolo & 277 \\
\hline 1775 & Francesc QUERALT & La Mercè & Església nova & 276 \\
\hline 1779 & Francesc QUERALT & Trinitaris descalços & Beat Miquel dels Sants & 243 \\
\hline 1782 & Pere Antoni MONLLEÓ & Santa Maria del Mar & Altar major & 244 \\
\hline 1784 & Francesc QUERALT & Caputxins & Beat Llorenç de Brindisi & 278 \\
\hline 1784 & Pere Antoni MONLLEÓ & Caputxins & Beat Llorenç de Brindisi & 279 \\
\hline 1787 & Francesc QUERALT & Mínims & Beat Gaspar de Bono & 245 \\
\hline 1787 & Pere Antoni MONLLEÓ & Mínims & Beat Nicolau de Longobardi & 246 \\
\hline 1790 & Francesc QUERALT & Sant Felip Neri & Oratori vespertí & 287 \\
\hline
\end{tabular}




$\begin{array}{lll}\text { s. d. (1781?) } & \text { Francesc QUERALT } & \text { Sant Felip Neri } \\ \text { s. d. } & \text { Francesc QUERALT } & \text { Sant Felip Neri } \\ \text { s. d. } & \text { Francesc QUERALT } & \text { Sant Felip Neri } \\ \text { s. d. } & \text { Francesc ANDREVÍ } & \text { Sant Felip Neri } \\ \text { s. d. } & \text { Ramon ALEIX } & \text { Sant Felip Neri }\end{array}$

Oratori vespertí

Oratori vespertí 